\title{
Female size and pre-copulatory sexual selection by males of intertidal snail (Littorina saxatilis)
}

\section{Nora Alsafi}

Department of Integrative Biology, College of Biological Sciences, University of Guelph, Guelph, ON Canada. Faculty supervisor: Elizabeth Boulding. For correspondence, please email: nora.alsafi@gmail.com.

\section{Abstract}

Sexual selection involves mate choice and competition for mates; it is one of the driving forces of evolution and may be a significant contributor to partial reproductive isolation. L. saxatilis, the rough periwinkle, is highly promiscuous and polyandrous; female $L$. saxatilis snails rarely reject male advances. While females are usually the choosier sex in nature, sexual selection by males is the norm for $L$. saxatilis. In this study I investigated male sexual selection based on female size for the crab ecotype of Spanish L. saxatilis. Male and female snails were measured and placed in mating arenas. Males were presented with a choice of a smaller or larger female relative to themselves. Mating frequency and duration was recorded. A total of 19 successful trials were performed. A significantly higher mating frequency $(p<0.005)$ was associated with larger females, indicating that males exhibited a strong mating preference for larger females. Mating duration, an indication of successful sperm transfer, was also significantly longer with larger females $(p<0.05)$. These results indicate that strong sexual selection by males exists for $L$. saxatilis, in which larger females are preferred. This behavior may be a response to perceived fecundity of females based on size.

Keywords: Littorina saxatilis, sexual selection, marine gastropods, mating duration

\section{Introduction}

Sexual selection involves non-random mating with the opposite sex and can impact intraspecific variation in morphological, physiological, and behavioural traits (Edward, 2015). Sexual selection can be pre-copulatory, or postcopulatory. Pre-copulatory selection involves mate choice by females and/or males (Paul, 2002). Pre-copulatory selection mechanisms include male-male competition, and female/male choice of mates. Understanding patterns of mate choice can provide insight into the nature of a species' evolutionary history, and how it may evolve in the future (Paul, 2002). Females are usually the selective sex in nature, because they often incur higher costs of reproduction (Edward, 2015). Avoiding excessive mating is often necessary to prevent damage or loss of female fitness (Edward, 2015). However, in some species, such as Littorina saxatilis, males are the choosy sex. The evolution of multiple mating observed in polyandrous species like $L$. saxatilis is of interest because it deviates from the typical pattern of female choice.

The rough periwinkle, $L$. saxatilis, a marine gastropod that inhabits rocky intertidal zones, is a model species for studying sexual selection as it deviates from the typical pattern of female choice. Two ecotypes, the "crab" and "wave" ecotype, exist in separate microhabitats, each possessing distinct physical characteristics; these traits help them tolerate differing environmental conditions. With no free-swimming larval stage and low adult dispersal, gene flow between $L$. saxatilis populations in different microhabitats is low, thus preserving the existing ecotypes (Erlandsson and RolánAlvarez, 1998). Different shell sizes allow the ecotypes to cope with different environments; genetic differences exist between ecotypes for several fitness-related traits (e.g. fecundity) (Conde-Padin et al., 2008). Rare hybrids between the ecotypes have shown evidence of reproductive dysfunction and are less fit than their parents (Hull, 1996).

Littorina saxatilis has a highly promiscuous, polyandrous mating system, with broods commonly being sired by approximately 20 different males (Johannesson et al., 2016). Female $L$. saxatilis snails are rarely seen to reject male advances (Johannesson et al., 2016). The costs of additional mating may be high for females (Johannesson et al., 2016). Such costs can be physical, as females fight with males as they reject mating advances; or time spent mating may reduce time available for foraging (Johannesson et al., 2016). However, $L$. saxatilis is a highly polyandrous species, which suggests that 1) females cannot assess male quality prior to mating and/or 2) genetic diversity of offspring is advantageous in their 
environment and/or 3) polyandry allows for larger brood size and number where the availability of high quality sperm is limited (Johannesson et al., 2016). Additionally, the cost of rejecting mating may be high-females may accept many matings because it is less costly than rejection (Johannesson et al., 2016). Females are not the choosy sex for L. saxatilis; males have been shown to exert pre-copulatory sexual selection towards females on the basis of size. Males incur higher mating costs than females, thus seem to be choosier in discriminating between females (Hintz-Saltin, Schade, \& Johannesson, 2013).

Male reproductive costs include sperm competition, and the energy cost and risk of searching for females (Dewsbury, 1982). Searching for mates involves a high energy cost, as mucous production for movement is a significant proportion of a snail's energy budget (Hintz-Saltin, Schade, \& Johannesson, 2013). For example, in L. littorea, this energy cost is about $25 \%$ of its energy budget (Hintz-Saltin, Schade, \& Johannesson, 2013). Also, searching for mates increases the risk of predation and dislodgement from rocks. Thus, males may seek to increase reproductive success by choosing females with the highest reproductive value (Hintz-Saltin, Schade, \& Johannesson, 2013) This value is associated with female size in $L$. saxatilis, with larger females producing larger clutches, more eggs/clutch, and a higher hatching rate (Conde-Padin et al., 2008; Hull, 1996; Zahradnik, Lemay \& Boulding, 2008; Erlandsson \& Johannesson 1994). The size difference (shell height) between male and females in $L$. saxatilis is $\sim 0.4 \mathrm{~mm}$ in the crab ecotype (Johannesson \& Johannesson, 1996). While males cannot distinguish between males/females prior to mating, they can select for shell size.

Size-based sexual dimorphism, in which one sex is larger than the other, is common in nature ( $\mathrm{Ng}$ et al., 2019). Marine gastropod females are larger than males in most species $(\mathrm{Ng}$ et al., 2019; Johannesson \& Johannesson, 1996). Size-based sexual dimorphism in marine gastropods may be a result of sexual selection, if fecundity favours larger females, or it may be driven not by sexual selection, but by other components of natural selection ( $\mathrm{Ng}$ et al., 2019). Evidence points towards the latter for marine gastropods, with other components of natural selection driving size-based sexual dimorphism ( $\mathrm{Ng}$ et al., 2019).

Marine gastropods are useful organisms of study, as their behavioural mechanisms towards sexual selection can be studied in situ (Ng et al., 2019). Male littornids can increase their reproductive success by selecting larger females, as they have been shown to produce more clutches and/or more eggs per clutch (Hintz-Saltin et al. 2013; Zahradnik et al., 2008).

L. saxatilis males have been shown to mate with larger and more fecund females in several studies when experiments use one ecotype (Hintz-Saltin et al., 2013; Johannesson, Rolan-Alvárez, \& Ekendahl, 1995). Conversely, other studies have shown $L$. saxatilis males to initiate copulation more frequently with females of similar size when two ecotypes are used (Hollander et al., 2005). Size differences between ecotypes are large, with the crab ecotype being twice as large as the wave ecotype (Johannesson, Johannesson \& Rolán-
Alvarez 1993). When two ecotypes are used, Swedish $L$. saxatilis males choose females of their own ecotype more frequently, and mate with them for longer (Hollander et al., 2005). Due to the large size difference between ecotypes, copulation becomes physically more difficult and may explain why males mate within their ecotype in these experiments $(\mathrm{Ng}$ et al., 2019). Conversely, when a single ecotype is used, males tend to select larger females (Hintz-Saltin et al., 2013, Zahradnik et al., 2008). Male size also influences access to mates; larger males tend to outcompete smaller males and gain more access to females (Zahradnik et al., 2008). Studies showing $L$. saxatilis males to mate with larger females use mounting frequency (how often males choose large females) as a measure of mating success (Saur, 1990; Hintz-Saltin et al., 2013; Johannesson, Rolán-Alverez \& Ekendahl, 1995). However, mounting duration is a better estimator of mating success, due to the nature of sperm transfer (Hollander et al., 2005).

In littorinid gastropods, sperm is transferred in a fluid; in L. saxatilis, the penis is glued to the mantle of the female and sperm is transferred along a groove in the penis (Hollander et al., 2005). Littorinid mating typically lasts 10 to $20 \mathrm{~min}$ but can vary drastically across species (Johannesson et al., 2016). Mating duration of L. obtusata can range from 1 to $4.5 \mathrm{hrs}, 30$ to $45 \mathrm{~min}$ for L. picta, and only 5 to $10 \mathrm{~min}$ for L. pintado (Paterson, Partridge, \& Buckland-Nicks, 2001). Sperm transfer in $L$. saxatilis is correlated with mating duration; copulations shorter than 10 min may not result in successful transfer (Hollander et al., 2005). It is impossible to determine if successful sperm transfer has occurred without examining females for offspring after a mating event, but mating duration is an appropriate estimator of successful sperm transfer (Paterson et al., 2001; Saur, 1990; Hollander et al., 2005).

Pre-copulatory sexual selection differs across littorinid species; research on $L$. saxatilis shows mixed results regarding size-based selection by males when using both or only one ecotype. When size differences between males and females are large (as they are between ecotypes), mating is physically more difficult, and males tend not to choose the largest females. However, when one ecotype is used, males tend to select larger females. Furthermore, mating duration has not been used as an estimator of mating success in studies showing males to select larger females. This raises the question: as mating duration is an indicator of successful sperm transfer, do males mate for longer with females of different size? I hypothesized that $L$. saxatilis males within the crab ecotype exhibit a preference for females with higher reproductive value, i.e. larger females. If this is true, then males should mate with larger females more frequently and for longer durations than smaller females. The influence of male size and malelargest female size difference on mating duration was also investigated in this study. While larger males outcompete smaller ones for access to females, there is little evidence showing that they mate for longer; I predict male size will have no influence on mating duration (Zahradnik et al., 2008). Large size differences between females and males may make copulation difficult, however as size differences within an 
ecotype are smaller, I predict this size difference to have no influence on mating duration ( $\mathrm{Ng}$ et al., 2019).

\section{Methods}

The study was conducted in the Hagen Aqualab at the University of Guelph from October 15-November 2, 2018. Trials were conducted on Oct 24, Oct 27, Oct 30 and Nov 2. Snails were kept in $9 \mathrm{~mm}$ diameter petri dishes containing mesh-covered holes in a saltwater tank at $10{ }^{\circ} \mathrm{C}$. All snails used in the study were the upper shore crab ecotype or were hybrids between the wave ecotype and the crab ecotype that had been reared from crosses performed at AquaLab. The parents of the snails had been collected from Cabo Silleiro in Northeastern Spain (Rolán-Alvarez et al., 1999). Snails were sexed and measured in in the Summerlee Science Complex at the University of Guelph, using a dissecting microscope and electronic calipers. A petri dish full of water was placed under the microscope, and tweezers were used to hold snails in the correct position to sex them. Males were identified as having a penis extending from the right side of their head. Shells were measured length-wise along the longest part of the shell to the nearest $0.01 \mathrm{~mm}$. Most snails already had ID labels, but new ones were created for those that did not, which detailed: ecotype, sex, "N" signifying a previously unlabelled snail, and a number ID (e.g. RBFN03, RBFM04). Coloured rubber bands were placed around the closed petri dishes for sex identification - red rubber bands were used for females, green for males. Snails under $7 \mathrm{~mm}$ were deemed sexually immature (Batchelor, 2017) and were not used in the study and labelled with orange rubber bands. Heavily parasitized snails were not used in the study and were also labelled with orange rubber bands.

Mating trials were conducted in the Hagen Aqualab. Mating arenas consisted of petri dishes filled with saltwater (Batchelor, 2017; Ng et al., 2019; Hull 1998). A previous study using L. saxatilis at the University of Guelph used a cutoff of $30 \mathrm{~min}$ to indicate that successful sperm transfer had occurred (Batchelor, 2017). This experiment is a continuation of that study (using the same snails), and the same cutoff was used. Two females were chosen for each trial, with a shell size difference of at least $0.3 \mathrm{~mm}$ between them; while previous studies use differences of $\sim 1 \mathrm{~mm}$, this number was chosen due to the limited amount of females available. Average size difference between females was $0.86 \mathrm{~mm}$, which is within the natural range of female size variability ( $\mathrm{Ng}$ et al., 2019). All mentions of "larger/smaller" females are referring to the female's size relative to the other female. While the minimum size difference between females was absolute, the size of males used in each trial varied relative to females; some males were comparatively smaller, or larger. Females were placed equidistant to the male in the mating arena, and the start time of the trial was recorded. The start of mating was determined by males' penes probing under a female's shell for at least 2 to 3 min (Johannesson et al., 2016). The end of mating was recorded when mated pairs fully separated from each other. A mating was deemed successful if it lasted longer than $30 \mathrm{~min}$, the approximate time for successful sperm transfer to occur in L. saxatilis (Hollander et al., 2005). Trials were cut off at 60 min, and pairs were separated if still mating at $60 \mathrm{~min}$. Snails that had successfully mated were re-labelled with a pink rubber band before being returned to the tank. Scienceware Tech paint pens were used to label male shells to keep track of them during trials. Mated females were not re-used in subsequent trials, as males may exhibit post-copulatory sexual selection by choosing virgin females. All snails had previously been reared in the lab and kept separate, and all that had been previously mated were marked and labelled. A total of 22 trials were conducted over October 24, 27, 30 and November 2. Each trial was one male selection event. Females that had not been mated were re-used in subsequent trials. Males were re-used in subsequent trials.

\section{Data Analysis}

A binomial test was performed on mating frequency (the proportion of males that chose larger or smaller females out of 19 trials), using Microsoft Excel Analysis Toolpak, with $\mathrm{N}=19$. Mating frequency was a proportion out of 19 trials. Twenty-two-trials were conducted, but only trials resulting in a successful mating event were included in the binomial test $(\mathrm{N}=19)$.

The proportion of males that chose larger females differed across the 4 testing days (Oct 24, Oct 27, Oct 30 and Nov 2). To see if testing days had an influence on male mate choice, another binomial test was performed.

To investigate the influence of male size, femalefemale size difference, male-largest female size difference, and male mate choice on mating duration, an ANCOVA was run using XLSTAT in Microsoft Excel. Mating duration was set as the dependent variable; male size, female-female size difference, male-largest female size difference, and male mate choice were set as predictor variables. The ANCOVA results included a goodness of fit test, and an analysis of variance using the Fisher's F test. A Type III Sum of Squares Analysis was also calculated using XLSTAT to determine the relative contribution of each co-variant in determining mating duration.

To analyze the influence of male sexual selection on the number of unsuccessful mating events (duration $<30 \mathrm{~min}$ ), a binomial test was performed on unsuccessful mating events versus male choice (larger or smaller females).

\section{Results and Discussion}

Male and female size variation is shown in Figure 1. Variation in female size difference and male-largest female size difference is shown in Figure 2. Of the 22 trials conducted, 19 resulted in a successful mating event (duration $>30 \mathrm{~min}$ ). Of these trials, males chose the larger female 17 times. The binomial test for male sexual selection (choosing larger versus smaller females) resulted in a p-value of 0.000326 , indicating that males chose larger females at a significantly higher frequency than smaller females. There was no significant difference in male sexual selection over 
different test days, with p-values between blocks all being greater than 0.3; the results of this binomial test are displayed in Table 1.

The mean duration of mating with larger females was $53.7 \mathrm{~min}$, and $40.6 \mathrm{~min}$ with smaller females, as shown in Figure 3. ANCOVA results are displayed in Table 2. Male size, female-female size difference, and male-largest female size difference had no significant effect on mating duration ( $\mathrm{p}$ $>0.4$ ). Male sexual selection (whether males chose larger vs. smaller females) had a significant effect on mating duration ( $p$ $<0.05$ ). Data for mating duration in relation to male size, female-female size difference, and male-largest female size difference for each trial are displayed in Figure 4, Figure 5 and Figure 6, respectively.

\section{Sexual Selection}

A highly significant preference for mating with larger females was observed in this study $(\mathrm{p}<0.0005)$; these results mirror those found in current scientific literature regarding male littorinid sexual selection (Saur, 1990; Erlandsson \& Alvarez, 1998; Erlandsson \& Johannesson, 1994). Sexual selection is one of the driving forces of evolution. Male $L$. saxatilis snails may be allocating sperm based on perceived fecundity of females, as larger females have been shown to produce larger and more numerous clutches (Zahradnik et al., 2008).

Determining the mechanism(s) behind mate choice for this ecotype is necessary to gain insight towards the evolution of choice. The results of this study suggest that males exhibit strong pre-copulatory selection towards females, on the basis of size. This selection may improve mating success, as larger females are more fecund; additionally, mating duration was significantly longer with larger females, indicating that successful sperm transfer is more likely to have occurred.

Determining fecundity of females by evaluating clutch size and number of clutches was beyond the scope of this study, but would be a logical next step for determining the mechanism(s) of sexual selection in this species; performing the same experiment on the wave ecotype would also provide further insight on mating patterns across ecotypes.

\section{Mating Duration}

Longer mating duration may increase the likelihood of successful sperm transfer, but copulation does not necessarily indicate successful sperm transfer (Saur, 1990; Paterson et al., 2001). The only way to determine if copulation was successful is to observe if offspring are produced; this was beyond the time constraints of this study. Whether successful sperm transfer had a relationship with mating duration in this study cannot be determined. As the penis is glued to the female's mantle after insertion, and sperm is transferred via ciliary movements along the penile groove, the mating process is long (Hollander et al., 2005). As such, copulation duration may be a better estimator of mating success than mounting frequency (Hollander et al., 2005). This study found that copulation duration was longer when males chose larger females, suggesting that these copulation events were more successful (resulted in sperm transfer).

\section{Female Size}

The results of this study indicate that male sexual selection (choice of larger vs. smaller females) significantly affects mating duration, with larger females having longer mating events. Similar results have been found for L. littorea, in which males mated with larger females of their own species for much longer than with other males, females of other species, or smaller females (Saur, 1990). A similar trend was observed for $L$. saxatilis in relation to sexual selection in some studies (Rolán-Alvarez et al., 1999). Similar results were found by $\mathrm{Ng}$ et al. (2019), the general trend across multiple species being towards positive sexual selection on female size for the crab ecotype.

Previous studies examining male sexual selection in $L$. saxatilis and $L$. littorea found no significant difference in mating duration for smaller versus larger females (Saur, 1990), contrasting with the results of this study. However, Saur (1990) included parasitized females, and when this data was excluded, a significant difference was found $(\mathrm{p}<0.025)$ (Saur, 1990). While heavily parasitized females were not included in this study, it is possible that some females with low levels of parasites unobservable by microscope were used in the trials. It has been shown that parasitized females have low fecundity or are often sterile (Saur, 1990). Males of $L$. littorea have been shown to mate for less time with parasitized females (Saur, 1990). Other factors such as predation risk, wave exposure, etc., may affect mating duration, but were not involved in this experiment (Koch et al., 2007); Pardo \& Johnson, 2006). Other factors influencing mating duration could be age and fitness.

Male-largest female size difference did not significantly affect mating duration; similar results were found in a mixedspecies study including L. saxatilis (Ng et al., 2019).

\section{Male Size}

Male size did not significantly influence mating duration in this study. The effect of male size differs across littorinid species; Hintz-Saltin et al. (2013) found that larger L. fabalis males tended to copulate for longer than smaller ones, while $\mathrm{Ng} \&$ Williams (2014) found that larger L. ardouiniana males mated for significantly longer than smaller males, although all males mated for longer with large females. Experiments on $L$. neglecta have shown no relationship between male size and copulation length (Johnson, 1999). Larger males may also have an advantage in initiating copulation; larger $L$. ardouiniana males have been found to physically exclude smaller males from copulation when both were competing for a female (Ng \& Williams, 2014).

Male crab ecotype $L$. saxatilis snails showed a strong preference for larger females in this study; this choice significantly affected mating duration, with larger females having longer mating events. Pre-copulatory sexual selection by male $L$. saxatilis snails within ecotypes has been 
investigated in other studies; males tend to choose larger females because they are more fecund, with more clutches and eggs/clutch. However, the effect of male pre-copulatory selection on mating duration had not been studied. Copulation with larger females may be more successful due to the higher likelihood of sperm transfer as time increases. Investigating whether sperm transfer is more succcesful with larger females is a prudent next step for this study.

\section{Acknowledgements}

I'd like to thank Dr. Elizabeth Boulding for her continued support throughout my project, and for her support in writing this paper. Your advice and support was greatly appreciated. I'd also like to thank Matt Cornish at the Hagen Aqualab for helping me with equipment and help setting up my experiment.

\section{References}

Batchelor, R. 2017. Sex at a snail's pace: male preference and mate selection in the marine gastropod species Littorina saxatilis. Unpublished undergraduate project report for IBIO*4500, University of Guelph.

Birkhead, T. R., \& Pizzari, T. (2002). Postcopulatory sexual selection. Nature Reviews Genetics, 3(4), 262-273. doi:10.1038/nrg774

Conde-Padin, P., Carballo, M., Caballero, A., \& RolanAlvarez, E. (2008). The relationship between hatching rate and number of embryos of the brood pouch in Littorina saxatilis. Journal of Sea Research, 60(3), 223225. doi:10.1016/j.seares.2008.06.003

Dewsbury, D. A. (1982). Ejaculate cost and male choice. American Naturalist, 119(5), 601-610. doi: $10.1086 / 283938$

Edward, D. A. (2015). The description of mate choice. Behavioral Ecology, 26(2), 301-310. doi:10.1093/beheco/aru142

Erlandsson, J., \& Rolan-Alvarez, E. (1998). Sexual selection and assortative mating by size and their roles in the maintenance of a polymorphism in Swedish Littorina saxatilis populations. Hydrobiologia, 378, 59-69. doi:10.1023/a:1003277202763

Erlandsson, J., \& Johannesson, K. (1994). Sexual selection on female size in a marine snail, Littorina-littorea (L). Journal of Experimental Marine Biology and Ecology, 181(2), 145-157. doi:10.1016/0022-0981(94)90125-2

Hollander, J., Lindegarth, M., \& Johannesson, K. (2005). Local adaptation but not geographical separation promotes assortative mating in a snail. Animal Behaviour, 70(5), 1209-1219.

Hull, S. L. (1998). Assortative mating between two distinct micro-allopatric populations of Littorina saxatilis (Olivi) on the northeast coast of England. Hydrobiologia, 378, 79-88. doi:10.1023/a:1003237521419

Johannesson, K., RolanAlvarez, E., \& Ekendahl, A. (1995). Incipient reproductive isolation between two sympatric morphs of the intertidal snail Littorina saxatilis. Evolution, 49(6), 1180-1190. doi:10.1111/j.15585646.1995.tb04445.x

Johannesson, B., \& Johannesson, K. (1996). Population differences in behaviour and morphology in the snail Littorina saxatilis: Phenotypic plasticity or genetic differentiation? Journal of Zoology, 240, 475-493.

Johannesson, B., \& Johannesson, \& RolanAlvarez, E. (1993). Morphological differentiation and genetic cohesiveness over a microenvironmental gradient in the marine snail Littorina saxatilis. Evolution, 47(6), 1770-1787.

Johannesson, K., Saltin, S. H., Charrier, G., Ring, A. K., Kvarnemo, C., Andre, C., \& Panova, M. (2016). Nonrandom paternity of offspring in a highly promiscuous marine snail suggests postcopulatory sexual selection. Behavioral Ecology and Sociobiology, 70(8), 1357-1366. doi:10.1007/s00265-016-2143-x

Johannesson, K., Saltin, S. H., Duranovic, I., Havenhand, J. N., \& Jonsson, P. R. (2010). Indiscriminate males: mating behaviour of a marine snail compromised by a sexual conflict? Plos One, 5(8). doi:10.1371/journal.pone.0012005

Johnson, L. J. (1999). Size assortative mating in the marine snail Littorina neglecta. Journal of the Marine Biological Association of the United Kingdom, 79(6), 1131-1132. doi:10.1017/s0025315499001423

Koch, N., Lynch, B., \& Rochette, R. (2007). Trade-off between mating and predation risk in the marine snail, Littorina plena. Invertebrate Biology, 126(3), 257-267. doi:10.1111/j.1744-7410.2007.00095.x

Makinen, T., Panova, M., \& Andre, C. (2007). High levels of multiple paternity in Littorina saxatilis: Hedging the bets? Journal of Heredity, 98(7), 705-711. doi:10.1093/jhered/esm097

Ng, T. P. T., \& Johannesson, K. (2016). No precopulatory inbreeding avoidance in the intertidal snail Littorina saxatilis. Journal of Molluscan Studies, 82, 213-215. doi:10.1093/mollus/eyv035

Ng, T. P. T., Rolan-Alvarez, E., Dahlen, S. S., Davies, M. S., Estevez, D., Stafford, R., \& Williams, G. A. (2019). The causal relationship between sexual selection and sexual size dimorphism in marine gastropods. Animal Behaviour, 148, 53-62. doi:10.1016/j.anbehav.2018.12.005

Ng, T. P. T., \& Williams, G. A. (2014). Size-dependent male mate preference and its association with size-assortative 
mating in a mangrove snail, Littoraria ardouiniana. Ethology, 120(10), 995-1002. doi:10.1111/eth.12271

Pardo, L. M., \& Johnson, L. E. (2006). Influence of water motion and reproductive attributes on movement and shelter use in the marine snail Littorina saxatilis. Marine Ecology Progress Series, 315, 177-186. doi:10.3354/meps315177

Paterson, I. G., Partridge, V., \& Buckland-Nicks, J. (2001a). Multiple paternity in Littorina obtusata (Gastropoda, Littorinidae) revealed by microsatellite analyses. Biological Bulletin, 200(3), 261-267. doi: $10.2307 / 1543508$

Paterson, I. G., Partridge, V., \& Buckland-Nicks, J. (2001b). Multiple paternity in Littorina obtusata (Gastropoda, Littorinidae) revealed by microsatellite analyses. Biological Bulletin, 200(3), 261-267. doi:10.2307/1543508

Paul, A. (2002). Sexual Selection and Mate Choice. International Journal of Primatology, 23(4), 877-904. doi:10.1023/a:1015533100275

Rolán-Alvarez, E., Erlandsson, J., Johannesson, K., \& Cruz, R. (1999). Mechanisms of incomplete prezygotic reproductive isolation in an intertidal snail: testing behavioural models in wild populations. Journal of Evolutionary Biology, 12(5), 879-890. doi:10.1046/j.1420-9101.1999.00086.x

Saltin, S. H., Schade, H., \& Johannesson, K. (2013). Preference of males for large females causes a partial mating barrier between a large and a small ecotype of Littorina fabalis (W. Turton, 1825). Journal of Molluscan Studies, 79, 128-132. doi:10.1093/mollus/eyt003

Saur, M. (1990). Mate discrimination Littorina-Littorea (L) and Littorina-Saxatilis (Olivi) (Mollusca, Prosobranchia). Hydrobiologia, 193, 261-270. doi:10.1007/bf00028082

Zahradnik, T. D., Lemay, M. A., \& Boulding, E. G. (2008). Choosy males in a littorinid gastropod: male Littorina subrotundata prefer large and virgin females. Journal of Molluscan Studies, $\quad 74, \quad 245-251$. doi:10.1093/mollus/eyn014 


\section{Tables}

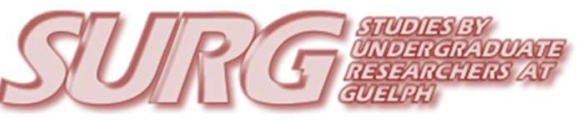

Table 1. P-values of pairwise binomial tests performed on the proportion of successful mating observed on each test day.

\begin{tabular}{|l|l|l|l|}
\hline \multicolumn{1}{|l|}{ Date } & 24 Oct, 2018 & 27 Oct, 2018 & 30 Oct, 2018 \\
\hline 24 Oct, 2018 & $\mathrm{X}$ & 0.34 & 0.40 \\
\hline 27 Oct, 2018 & 0.34 & $\mathrm{X}$ & 1 \\
\hline 30 Oct, 2018 & 0.39 & 1 & $\mathrm{X}$ \\
\hline 2 Nov 2018 & 0.75 & 0.24 & 0.29 \\
\hline
\end{tabular}

Table 2. ANCOVA test results using a Fisher's $F$ test, and Type III Sum of Squares Analysis for mating duration, as determined by male size, female size difference, male-largest female size difference, and male sexual selection (choice of larger vs. smaller female relative to male). Independent variable: male sexual selection covarying with male size, female size difference, and male-largest female size difference.

\begin{tabular}{|c|c|c|c|c|c|}
\hline \multicolumn{2}{|c|}{ Type III SS } & df & Mean Square & F & P-value \\
\hline Male Size & 0.032 & 1 & 0.032 & 0.351 & 0.559 \\
\hline $\begin{array}{c}\text { Female } \\
\text { Size Difference }\end{array}$ & 0.002 & 1 & 0.002 & 0.019 & 0.892 \\
\hline $\begin{array}{c}\text { Male- } \\
\text { Largest Female } \\
\text { Size Difference }\end{array}$ & 0.069 & 1 & 0.069 & 0.643 & 0.430 \\
\hline $\begin{array}{c}\text { Male } \\
\text { Sexual Selection }\end{array}$ & 0.421 & 1 & 0.421 & 4.615 & 0.042 \\
\hline
\end{tabular}


Female size and pre-copulatory sexual selection by males of intertidal snail (Littorina saxatilis) (Alsafi)

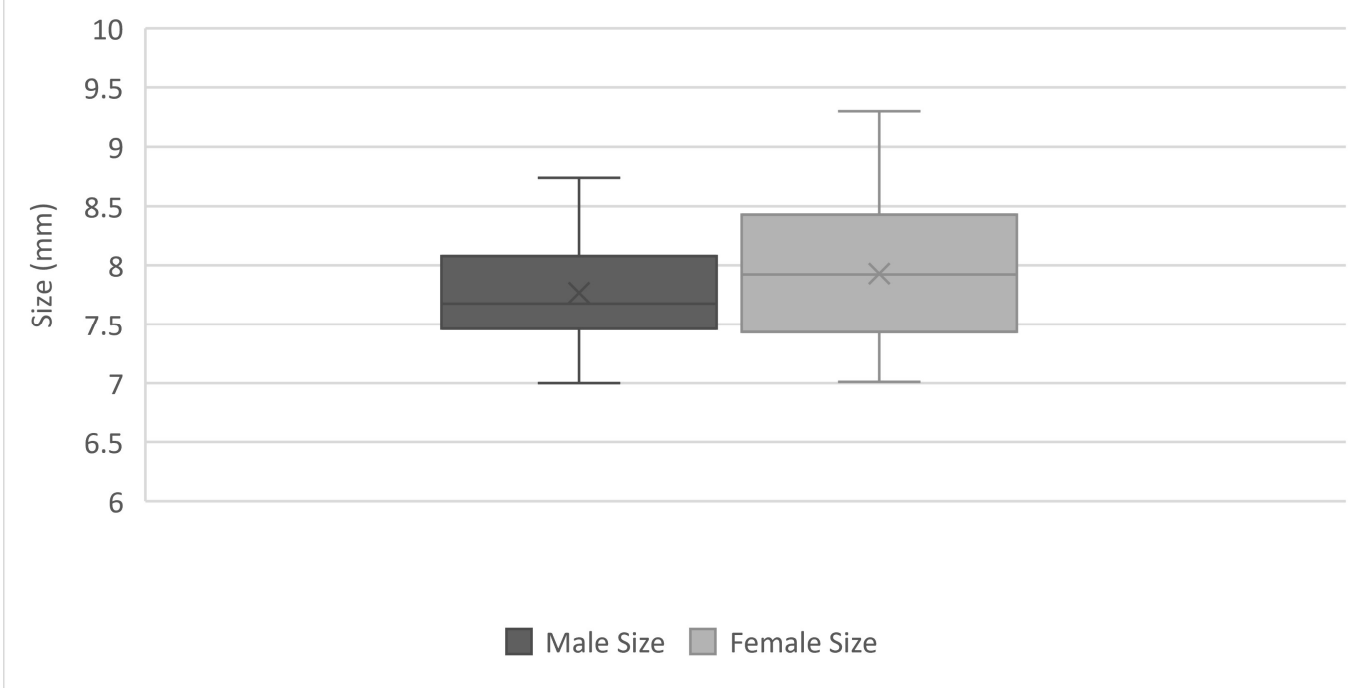

Figure 1. Size variation of $L$. saxatilis males and females used in the study.

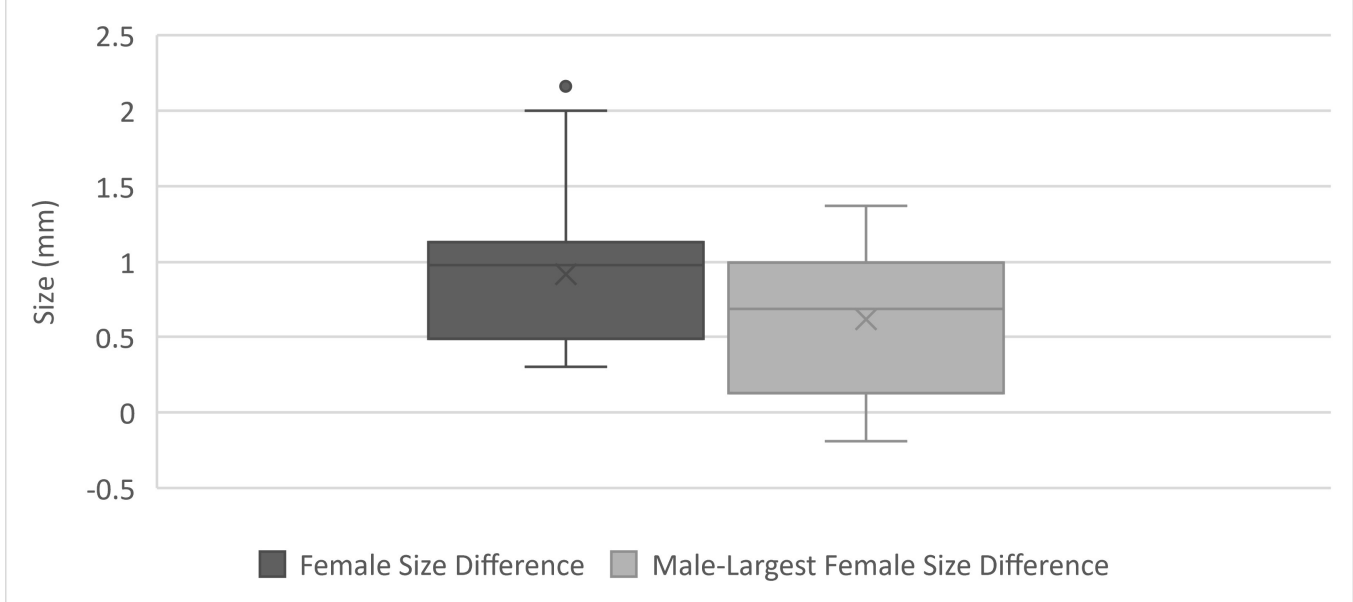

Figure 2. Variation in L. saxatilis female-female size difference and male-largest female size difference 
Female size and pre-copulatory sexual selection by males of intertidal snail (Littorina saxatilis) (Alsafi)

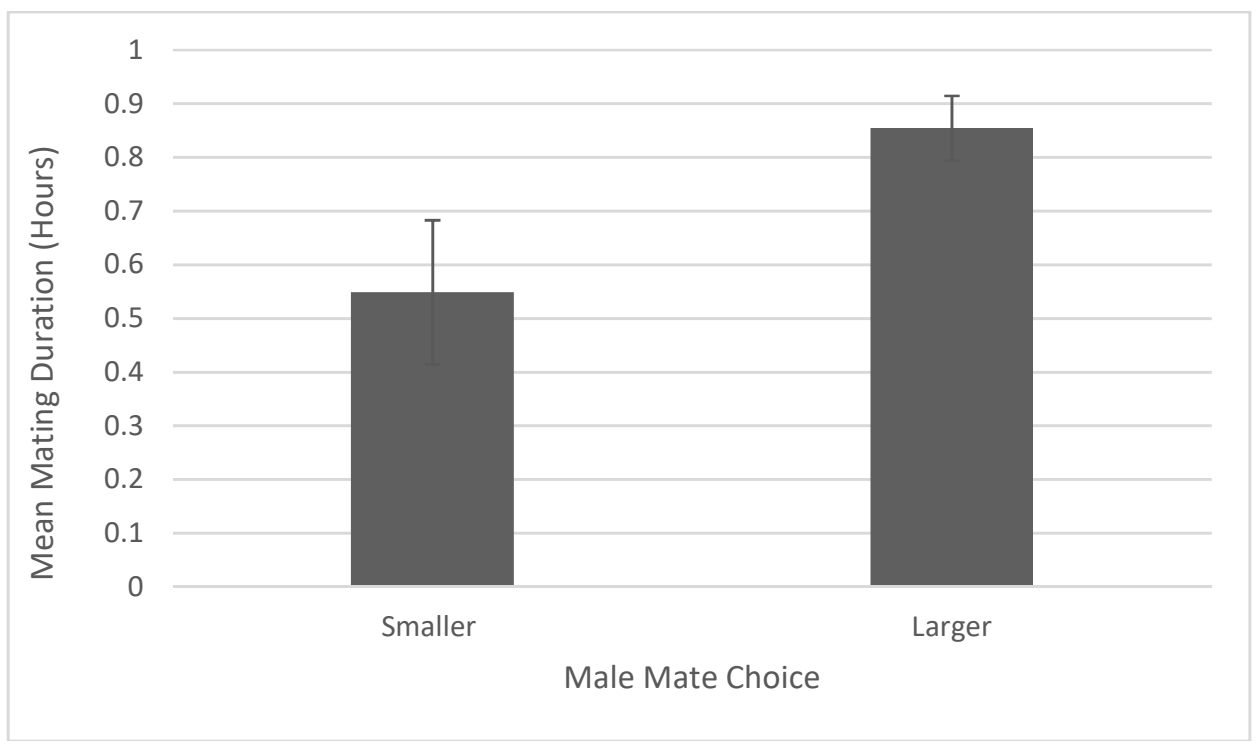

Figure 3. Mate choice by L. saxatilis males (whether they chose larger or smaller females) and its relationship to mean mating duration.

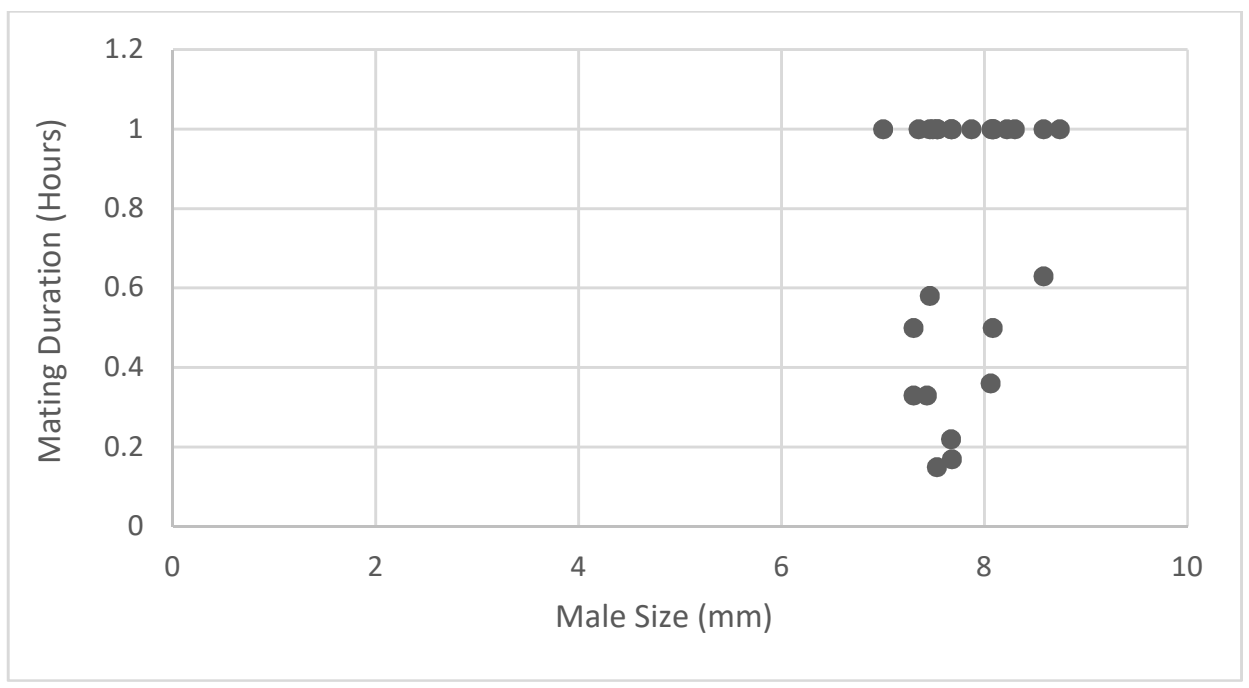

Figure 4. L. saxatilis male size and mating duration for each trial. 
Female size and pre-copulatory sexual selection by males of intertidal snail (Littorina saxatilis) (Alsafi)

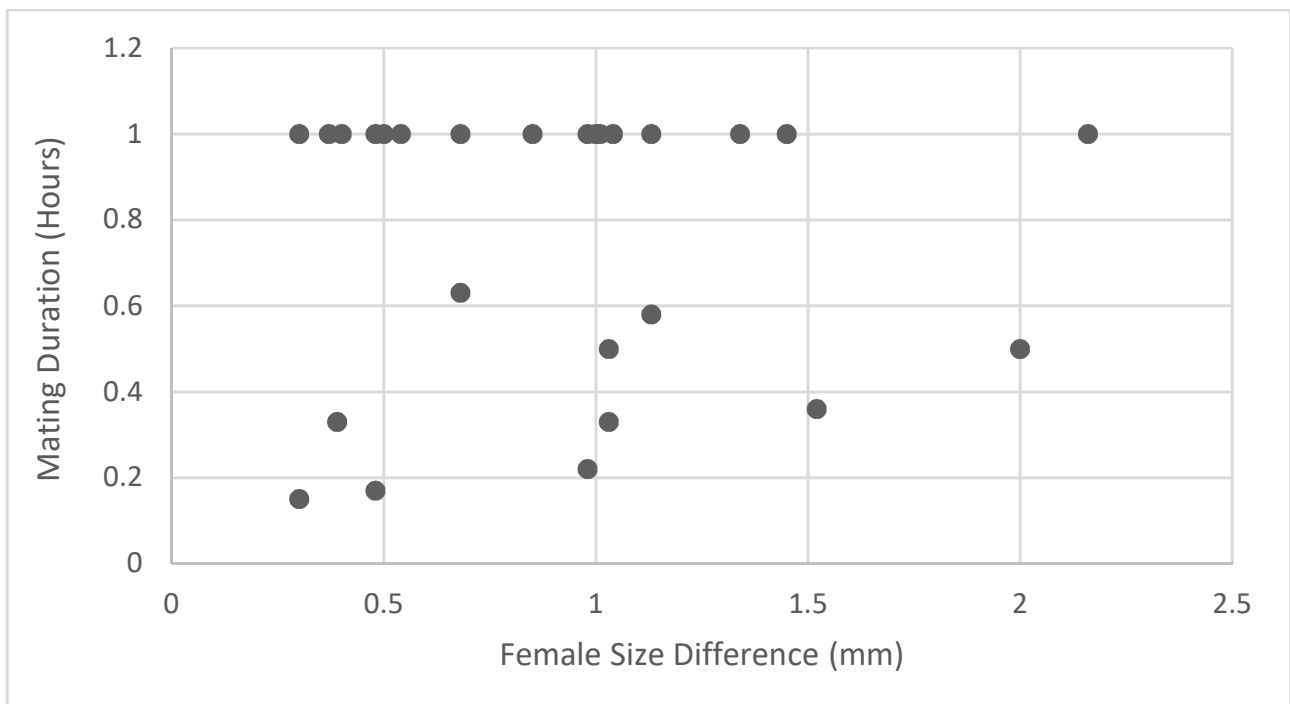

Figure 5. L. saxatilis female size difference and mating duration for each trial.

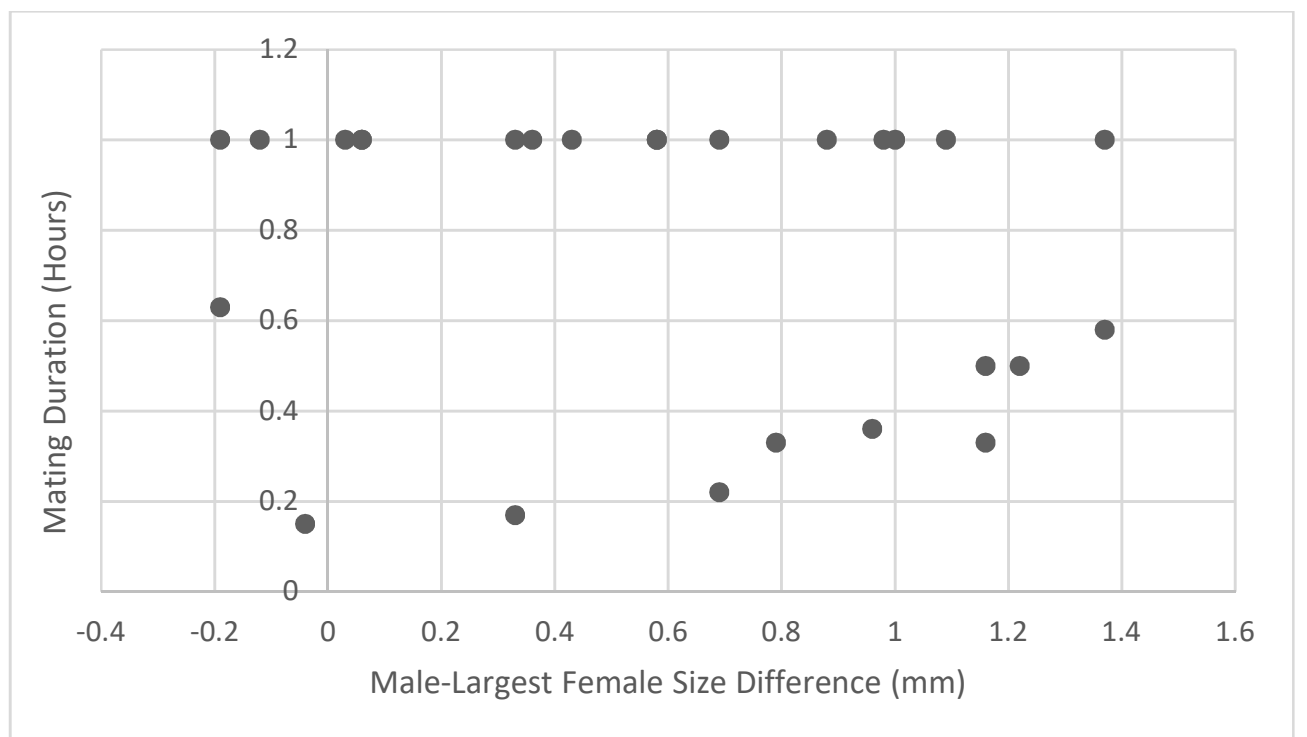

Figure 6. L. saxatilis male-largest female size difference and mating duration for each trial. 
Female size and pre-copulatory sexual selection by males of intertidal snail (Littorina saxatilis) (Alsafi)

Appendix A

\begin{tabular}{|c|c|c|c|c|c|c|c|c|c|c|c|}
\hline DATE & TRIAL & MALE ID & FEMALE 1 ID & $\begin{array}{l}\text { FEMALE } 2 \\
\text { ID }\end{array}$ & $\begin{array}{l}\text { MALE } \\
\text { SIZE }\end{array}$ & $\begin{array}{l}\text { FEMALE } \\
1 \text { SIZE }\end{array}$ & $\begin{array}{l}\text { FEMALE } \\
2 \text { SIZE }\end{array}$ & $\begin{array}{l}\text { DILE } \\
\text { DIFFERENCE } \\
(\mathrm{mm})\end{array}$ & $\begin{array}{l}\text { WITH } \\
\text { LARGE/SMALL }\end{array}$ & $\begin{array}{l}\text { Duration } \\
\text { (hours) }\end{array}$ & SUCCESSFUL? \\
\hline 24-Oct & Trial 1 & RBMN13 & RBF213 & RBF28S16 & 7.80 & 8.68 & 7.52 & 1.16 & & & NO \\
\hline 24-Oct & Trial 2 & RBMN21 & RB066S16F -8.44 & RBFN12 & 8.08 & 8.44 & 7.10 & 1.34 & Larger & 1.00 & YES \\
\hline 24-Oct & Trial 3 & RBMN06 & FN04 & RB175S16 & 7.67 & 8.36 & 7.38 & 0.98 & Smaller & 0.22 & NO \\
\hline 24-Oct & Trial 3 & RBMN06 & FN04 & RB175S16 & 7.67 & 8.36 & 7.38 & 0.98 & Larger & 1.00 & YES \\
\hline 24-Oct & Trial 4 & RBF05F1 & RB117FS16 & HYF03F17 & 7.87 & 7.44 & 8.45 & 1.01 & Larger & 1.00 & YES \\
\hline 24-Oct & Trial 5 & RBM07 & RB044S16 & FRB01F18 & 7.68 & 8.01 & 7.53 & 0.48 & Larger & 0.17 & NO \\
\hline 24-Oct & Trial 5 & RBM07 & RB044S16 & FRB01F18 & 7.68 & 8.01 & 7.53 & 0.48 & Larger & 1.00 & YES \\
\hline 24-Oct & Trial 6 & RBMN15 & RBFN18 & RB101S18 & 7.00 & 7.90 & 7.10 & 0.80 & & & NO \\
\hline 24-Oct & Trial 7 & RB047S16 & RBF02F17 & RB005S16 & 7.53 & 7.19 & 7.49 & 0.30 & Smaller & 0.15 & NO \\
\hline $24-O c t$ & Trial 7 & RB047S16 & RBF02F17 & RB005S16 & 7.53 & 7.19 & 7.56 & 0.37 & Larger & 1.00 & YES \\
\hline 24-Oct & Trial 8 & RBMN03 & RB032S16 & RBF18S16 & 7.00 & 7.05 & 8.09 & 1.04 & Smaller & 1.00 & YES \\
\hline 27-Oct & Trial 9 & RBM05F16 & RBFN16 & RB052S16 & 8.58 & 8.39 & 7.71 & 0.68 & Smaller & 20.00 & NO \\
\hline 27-Oct & Trial 9 & RBM05F16 & RBFN16 & RB052S16 & 8.58 & 8.39 & 7.71 & 0.68 & Larger & 0.63 & YES \\
\hline 27-Oct & Trial 10 & RB047S16 & RBFN22 & RB871S16 & 8.22 & 8.10 & 7.10 & 1.00 & Larger & 1.00 & YES \\
\hline 27-Oct & Trial 11 & RBF07F17 & RBF33S16 & RBF05S18 & 7.54 & 8.52 & 7.07 & 1.45 & Larger & 1.00 & YES \\
\hline 27-Oct & Trial 12 & RBMN06 & RBF18S16 & RBFN12 & 8.09 & 8.27 & 8.67 & 0.40 & Larger & 1.00 & YES \\
\hline 27-Oct & Trial 13 & RB043S16 & RBFN19 & RBF09F17 & 7.46 & 7.70 & 8.83 & 1.13 & Smaller & 7.00 & NO \\
\hline 27-Oct & Trial 13 & RB043S16 & RBFN19 & RBF09F17 & 7.46 & 7.70 & 8.83 & 1.13 & Larger & 0.58 & YES \\
\hline
\end{tabular}


Female size and pre-copulatory sexual selection by males of intertidal snail (Littorina saxatilis) (Alsafi)

\begin{tabular}{|c|c|c|c|c|c|c|c|c|c|c|c|}
\hline DATE & TRIAL & MALE ID & FEMALE 1 ID & $\begin{array}{l}\text { FEMALE } 2 \\
\text { ID }\end{array}$ & $\begin{array}{r}\text { MALE } \\
\text { SIZE }\end{array}$ & $\begin{array}{r}\text { FEMALE } \\
1 \text { SIZE }\end{array}$ & $\begin{array}{r}\text { FEMALE } \\
2 \text { SIZE }\end{array}$ & $\begin{array}{r}\text { DIFFERENCE } \\
(\mathrm{mm})\end{array}$ & $\begin{array}{l}\text { WITH } \\
\text { LARGE/SMALL }\end{array}$ & $\begin{array}{r}\text { Duration } \\
\text { (hours) }\end{array}$ & SUCCESSFUL? \\
\hline 30-Oct & Trial 14 & RB139S18 & RB101S16 & RBF05S18 & 7.30 & 7.43 & 8.46 & 1.03 & Larger & 0.50 & YES \\
\hline 30-Oct & Trial 15 & RBMN17 & RBFN18 & RBF07S16 & 7.49 & 7.01 & 7.55 & 0.54 & Larger & 1.00 & YES \\
\hline $30-O c t$ & Trial 16 & RB096S16 & RB052S16 & RBF18S16 & 7.43 & 7.83 & 8.22 & 0.39 & Smaller & 0.33 & NO \\
\hline $30-$ Oct & Trial 17 & RBMN02 & RB180S16 & RBFN12 & 8.30 & 7.02 & 9.18 & 2.16 & Larger & 1.00 & YES \\
\hline 30-Oct & Trial 18 & RB047S16 & RB190S16 & RB050S16 & 8.74 & 8.80 & 7.95 & 0.85 & Larger & 1.00 & YES \\
\hline 02-Nov & Trial 19 & RBF055S18 & RB180A16 & RB096S16 & 8.07 & 8.00 & 8.50 & 0.50 & Larger & 1.00 & YES \\
\hline 02-Nov & Trial 20 & RBF07F17 & RBF014S18 & RB050S16 & 7.35 & 8.05 & 8.35 & 0.30 & Larger & 1.00 & YES \\
\hline 02-Nov & Trial 21 & RBMN14 & RB182S16 & RBF07S16 & 8.06 & 9.02 & 7.50 & 1.52 & Smaller & 0.36 & YES \\
\hline 02-Nov & Trial 22 & RBMN13 & RB071S16 & RB043S16 & 8.08 & 7.30 & 9.30 & 2.00 & Larger & 0.50 & YES \\
\hline
\end{tabular}

